\title{
A IMPORTÂNCIA ESTRATÉGICA DO EMPENHO, LIQUIDAÇÃO E PAGAMENTO PARA A ORGANIZAÇÃO DO SETOR PÚBLICO
}

\author{
A. K. ARAÚJO e L. F. L. G. COSTA \\ Instituto Federal de Educação, Ciência e Tecnologia do Rio Grande de Norte \\ brasil@ifrn.edu.br \\ alissonkemis@hotmail.com; lucia.lucio@ifrn.edu.br \\ Artigo submetido em 26/07/2018 e aceito em 01/08/2018 \\ DOI: 10.15628/empirica.2018.7548
}

\section{RESUMO}

Esse estudo tem por intuito discorrer sobre as formas de planejamento da gestão pública, tendo como ponto de partida a carência de informação das pessoas que trabalham com a parte burocrática nos entes públicos, fato demonstrado diariamente e mensurado através de indicadores pelos veículos de comunicação onde se notam processos administrativos fraudados, informações de contratos superfaturados, direcionamento de editais de licitação entre outros. A formulação dos gastos públicos segue um fluxo onde os processos de compras passam por diversos setores e departamentos desde a solicitação inicial de uma despesa até a entrega dos produtos ou serviços, e nesse trâmite os agentes públicos são envolvidas muitas vezes sem saber a real responsabilidade do seu trabalho, por falta de informação e capacitação. 0 estudo tem como objetivo demonstrar a carência de informação das pessoas que trabalham com os três estágios clássicos da despesa que são o empenho, liquidação e pagamento. Ainda sobre esse tema o trabalho trata os benefícios que os três estágios podem contribuir com a organização do ambiente de trabalho pensando de forma estratégica e transparente para utilização dos recursos públicos por parte dos municípios, estados e federação.

PALAVRAS-CHAVE: Planejamento, Gestão Pública, Responsabilidade, Informação.

\section{THE STRATEGIC IMPORTANCE OF THE COMMITMENT, SETTLEMENT AND PAYMENT FOR THE ORGANIZATION OF THE PUBLIC SECTOR}

\begin{abstract}
This study aims to discuss the ways of planning public management, starting from the lack of information of people working with the bureaucratic part in public entities, a fact demonstrated daily and measured through indicators by the communication vehicles where notices of fraudulent administrative procedures, information on over dated contracts, targeting of bidding documents, among
\end{abstract}


others. The formulation of public expenditures follows a flow where the procurement processes pass through different sectors and departments from the initial request of an expense to the delivery of the products or services, and in this process the public agents are often involved without knowing the real responsibility of the their work, for lack of information and training. The study aims to demonstrate the lack of information of people working with the three classic stages of spending that are commitment, settlement and payment. Also on this theme, the work deals with the benefits that the three stages can contribute to the organization of the work environment thinking strategically and transparently for the use of public resources by the municipalities, states and federation.

KEYWORDS: Planning, Public administration, Responsibility, Information.

\section{INTRODUÇÃO}

Tendo em vista o cenário de recessão que o País viveu recentemente e os fatos envolvendo o erário público noticiados diariamente nas mídias do País, surge à necessidade de atentarmos para com a situação do nosso Estado, tanto política como principalmente econômica, e para tal surgem a cada dia indicadores que tentam mensurar o crescimento ou a retração da economia. A partir disso deve-se conhecer as formas pela qual as despesas são executadas pelos entes governamentais, daí surgiu o pensamento de escrever um trabalho direcionado para esse propósito.

0 presente estudo tem como objetivo demonstrar a carência de informação das pessoas que trabalham com os três estágios clássicos da despesa que são o empenho, liquidação e pagamento. Ainda sobre esse tema se evidenciará os benefícios que os três estágios podem contribuir com a organização do ambiente de trabalho pensando de forma estratégica e transparente para utilização dos recursos públicos por parte dos municípios, estados e federação. 0 artigo trabalha também a necessidade da interação dos usuários do sistema público, tanto na condição de gestor público como de credor que fornece materiais de consumo e serviços para os órgãos públicos. Para tratar desse assunto surge a necessidade de compreender o que é o empenho, liquidação e o pagamento.

Delimitada a temática, foram traçados os objetivos da pesquisa, tendo como objetivo geral que define o propósito da pesquisa. Demonstrar a carência de informação das pessoas que trabalham com os três estágios clássicos da despesa que são o empenho, liquidação e pagamento.

Surge à necessidade de prosseguir com o desenvolvimento do trabalho estudando a importância do empenho, liquidação e pagamento para o andamento das atividades dos órgãos públicos ao identificar os tipos de empenho e suas aplicabilidades no dia a dia e verificar o fluxo operacional e estratégico eficiente e eficaz.

A formulação dos gastos públicos passa pelas mãos de muita gente desde a solicitação inicial de uma despesa até a entrega dos produtos ou serviços, e nesse trâmite pessoas e mais pessoas são envolvidas muitas vezes sem saber a real responsabilidade do seu trabalho, por falta de informação e capacitação. A falta de capacitação trava a gestão e compromete o andamento dos serviços prestado a população e a preservação dos contratos assinados com os fornecedores. 


\section{ISSN - 2447-178X}

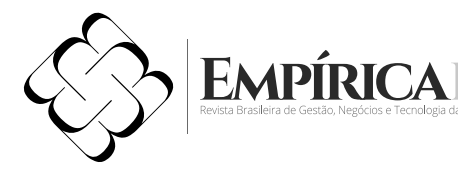

Assim, o estudo ganha cada vez mais relevância para tratar desse assunto para proporcionar aos funcionários públicos e a população em geral a conscientização da importância da burocracia eficiente na gestão pública. A informação é a chave para crescimento, uma sociedade informada contribui fiscalizando a aplicação dos recursos públicos, ela sabe se o dinheiro está sendo investido corretamente ou está sendo usado para favorecer agentes públicos. Diante dos dados expostos e resultados obtidos o estudo justifica-se plenamente.

Compreendidos os conceitos, a pesquisa tem característica descritiva, pois descreve as características inerentes ao contexto do orçamento público baseando-se nas referências estudadas e leis implantadas tanto na esfera federal como estadual.

Com relação aos métodos empregados, de início foram coletadas informações essenciais através de fontes como sites da internet, artigos publicados em site da área, livros, para obter informações sobre a área pesquisada, ou seja, foi realizada uma pesquisa bibliográfica, onde as ferramentas utilizadas foram computadores com acesso à internet para viabilizar o acesso aos conteúdos digitais e livros que contém os assuntos estudados e as informações essenciais para o andamento do estudo. Após a coleta de informações foi aplicado um questionário contendo dez perguntas para um universo de onze pessoas responsáveis por trabalhar diretamente com a parte burocrática a que o trabalho está relacionado, enriquecendo a pesquisa comas informações coletadas proporcionando assim efetuar uma analisar do perfil das pessoas que trabalham diretamente com a execução da despesa pública.

Os resultados serão apresentados através de uma discussão onde trará a importância desse tema para a organização e planejamento estratégico na gestão pública utilizando-se da logística proporcionada pelo fluxo contínuo que é o empenho, liquidação e pagamento. Para enriquecer a pesquisa será apresentado o perfil dos servidores responsáveis por essa logística partindo de ilustrações gráficas que proporcionarão uma discussão mais nobre sobre a necessidade de trabalhar corretamente o tema.

Finalizando a discussão, seguem as considerações finais e conclusões sobre a pesquisa onde se abordará de forma sucinta as partes analisadas no decorrer do trabalho, podendo delimitar futuras linhas de pesquisa para outros temas ou aprofundamento desse analisado no referido estudo.

\section{REVISÃO BIBLIOGRÁFICA}

Para compreender o processo de empenho, liquidação e pagamento, precisa-se saber como ele é estruturado desde o início onde a sua reserva é feita através das ferramentas que tem como objetivo planejar os gastos de cada gestão para os quatro anos de governo.

\subsection{Planejamento estratégico público}

De acordo com SANTOS (2012, p. 24), "o orçamento público é um dos principais instrumentos que o gestor público dispõe para dar cumprimento às suas funções e que, sem o amparo do orçamento público, ele pouco pode fazer".

0 orçamento é desenvolvido através do planejamento e para tal finalidade existem ferramentas propostas por lei que regulamentam o que os governantes devem fazer num determinado período de 
tempo, o planejamento de uma gestão é iniciado com o PPA (Plano Plurianual) que define as estratégias, diretrizes e metas do governo para o médio prazo, mais especificamente o período igual ao do mandato presidencial. Não se trata apenas de propor ações a serem implementadas em dado período, mas sim de instituir um plano de ação que, partindo de um planejamento estratégico, discrimine os objetivos de governo a serem perseguidos durante o mandato do chefe do poder executivo, estabeleça os programas setoriais a serem implementados e defina as fontes de financiamento e as metodologias de elaboração, gestão, avaliação e revisão dos programas. Definido o PPA, será iniciado o processo de execução das propostas estabelecidas durante o planejamento.

A LDO (Lei de Diretrizes Orçamentárias) é a lei orçamentária que faz a ligação entre o PPA e a LOA (Lei Orçamentária Anual). Ela cumpre diversas funções definidas pela Constituição Federal e pela Lei de Responsabilidade Fiscal. Para cumprir a função de levar para a LOA os objetivos e as metas definidas no PPA, a LDO estabelece as metas e as prioridades do governo para cada exercício e as regras a serem observadas na elaboração e na execução do orçamento anual. A finalidade original da LDO foi definida pela Constituição Federal, art. 164, §2o:

A Lei de Diretrizes Orçamentárias compreenderá as metas e prioridades da administração pública federal, incluindo as despesas de capital para o exercício financeiro subsequente, orientará a elaboração da Lei Orçamentária Anual, disporá sobre as alterações na legislação tributária e estabelecerá a política de aplicação das agências financeiras oficiais de fomento. (BRASIL, 1998).

Essa lei tem um papel muito importante de orientar os gastos mediante as arrecadações para o ano posterior de cada gestão, é aqui que as prioridades de investimento são definidas pela gestão e para tal surge à necessidade da conscientização da população de cobrar aos gestores audiências públicas e participar para que seja desenvolvido um orçamento participativo onde a população demonstre as prioridades de cada bairro, rua ou setor da cidade que seja evidenciada precariedades nos serviços fornecidos pelos entes públicos.

Elaborado PPA que estipula as metas para os quatro anos de gestão e a LDO que regulamenta todas as ações para efetivar as metas surge o momento de colocar todo o planejamento em ação e isso é feito através da LOA que elabora o plano de trabalho anual baseando-se nas receitas que o Estado planeja arrecadar para que a gestão cumpra com seu dever que é proporcionar a sociedade os serviços básicos provenientes na nossa constituição. Para que a despesa seja realizada, ela deve constar na LOA, porém nem tudo que está previsto nela é de obrigação do gestor executar.

Essas três leis citadas acima são as principais ferramentas utilizadas pelo governo para planejar a aplicação dos recursos advindos das receitas que entram nos cofres públicos.

\subsection{Efetividade na gestão pública}

A gestão pública atualmente passa por momentos conturbados onde noticiários demonstram a população percorrendo as ruas cobrando uma gestão pública pautada de seriedade, transparência e efetividade. 


\section{ISSN - 2447-178X}

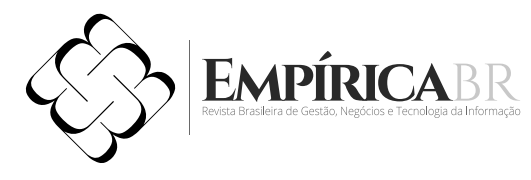

Mediante isso Brasil (2008, p.2), na "Lei n 11.653/2008 legitima as perspectivas anteriormente apresentadas ao estabelecer que a gestão do Plano Plurianual do período de 2008 a 2011 observara os princípios de eficiência, eficácia e efetividade na avaliação dos seus programas".

É preciso destacar que a avaliação sistemática, contínua e eficaz é uma ferramenta gerencial poderosa, fornecendo aos formuladores e gestores de políticas públicas condições para aumentar a eficiência e efetividade dos recursos aplicados. Faz-se necessário, portanto, o desenvolvimento de um conjunto harmônico e sistemático de indicadores que abranjam os a eficiência, eficácia e efetividade. (SANO; MONTENEGRO, 2013, p. 42).

Para mudar tais indicadores só através da educação, os servidores precisam se capacitar e cobrar dos gestores a informação para desenvolver um trabalho mais eficiente, só assim o País alcançará um patamar diferente e voltará a alçar voos mais longos.

\subsection{Processo de compras públicas e seu papel estratégico}

O processo de compras públicas é regulamentado pela lei nº 8.666, de 21 de junho de 1993, esta Lei estabelece normas gerais sobre licitações e contratos administrativos pertinentes a obras, serviços, inclusive de publicidade, compras, alienações e locações no âmbito dos Poderes da União, dos Estados, do Distrito Federal e dos Municípios (BRASIL, 1993).

O processo de compras públicas é planejado de forma que o município, estado ou governo proporcionem aos fornecedores a possibilidade de fornecer seus produtos ou serviços para o Estado através de processos licitatórios.

De acordo com art. 23 da Lei 8.666/93 o sistema de compras por Licitação é o procedimento administrativo para contratação de serviços ou aquisição de produtos pelos governos Federal, Estadual e Municipal ou entidades de qualquer natureza. Definindo empenho, liquidação e pagamento (BRASIL, 1993).

O procedimento de licitações tem como objetivo a igualdade, transparência e legitimidade. Deve orientar as práticas administrativas de forma a colocar a busca do interesse público como objetivo final das ações administrativas, ao contrário dos particulares, que dispõem de ampla liberdade quando pretende adquirir, alienar, locar bens, contratar a execução de obras ou serviços, o Poder Público, para fazê-lo, necessita adotá-lo como um procedimento preliminar rigorosamente determinado (CARVALHO, 2017, p 172).

O objetivo do processo licitatório é proporcionar ao órgão licitante adquirir o bem ou serviço almejado pelo melhor custo/benefício, seja uma carteira para escola ou um carro para a saúde, o processo envolve dinheiro público e como tal deve seguir os princípios da legalidade, impessoalidade, moralidade, publicidade e eficiência.

0 processo de licitação estabelece em seu corpo através de clausulas os procedimentos adotados por ambas as partes, contratante (governo) e contratada (empresa), para o andamento correto dos fornecimentos das mercadorias, liquidação e pagamentos estipulados em prazos no instrumento de contrato que é feito posteriores a finalização da licitação. 


\section{ISSN - 2447-178X}

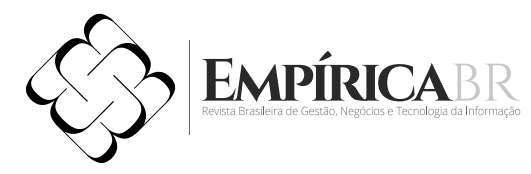

Passados os momentos da licitação e a assinatura do contrato vigente por um determinado período de tempo, a empresa começa a fornecer seus produtos/serviços ao ente público. A partir desse ponto surge a necessidade de aprofundar o tema para compreender a fundo como o andamento desse fluxo implicará no andamento correto ou não das cláusulas propostas no instrumento de contrato assinado pelo contratante e contratado.

\subsection{Empenho, liquidação e pagamento}

Passados os conceitos de orçamentos e as ferramentas utilizadas para a sua formulação, surge à necessidade de aprofundar o tema proposto nesse estudo que é energizar a discussão acerca de um ponto que demonstra insegurança e desinformação por parte dos agentes públicos que trabalham na burocracia do dia a dia nas entidades públicas, para entender o conceito de burocracia, segue algumas definições e pensamentos.

A burocracia estatal na gestão pública é uma doença crônica no Brasil e, de modo geral, coloca em coma induzido a população, que necessita da prestação positiva do Estado, na efetividade dos direitos sociais fundamentais, a fim de diminuir as desigualdades sociais e ao mesmo tempo promover o desenvolvimento econômico, garantindo, assim, a construção de uma sociedade livre, justa e solidária. (MANAF, SILVA, 2017. p.25)

Na linguagem comum a palavra burocracia assume, na grande maioria das vezes, uma conotação pejorativa. Burocracia usualmente é associada à ineficiência, ineficácia, atrasos, confusão, autoritarismo, privilégios e ainda a outros atributos negativos. As organizações modernas são descritas como uma ruptura fundamental com esses atributos da burocracia, tanto em parte da literatura especializada em administração, quanto na maioria da grande imprensa. (DE VASCONCELOS, 2004.p.200)

A burocracia é tratada por vezes como um mal que trava o sistema público tornando os serviços mais lentos e ineficientes perante os olhos da sociedade. Abaixo o raciocínio atentara para a importância de trabalhar o fluxo do empenho, liquidação e pagamento corretamente para o andamento das atividades dos órgãos públicos.

Empenho, é a reserva feita que garanta parte do orçamento do ano para efetuar o pagamento ao credor que o município desejar adquirir um bem ou serviço num determinado período de tempo.

Segundo o art. 58 da Lei n 4.320/1964, empenho é o ato emanado de autoridade competente que cria para o Estado obrigação de pagamento pendente ou não de implemento de condição. Consiste na reserva de dotação orçamentária para um fim específico.

Empenho é a reserva de parte da dotação orçamentária para fazer frente ao pagamento dos fornecedores contratados. Nenhum órgão pode realizar despesa sem prévio empenho (SANTOS, 2012). Como o autor expressa, o empenho é a reserva antecipada antes da despesa executada por parte do 
órgão público, quando a ordem de serviço ou compra é construída e encaminhada à empresa, essa deve ir anexada juntamente ao empenho que proporciona ao credor a garantia de que o dinheiro para efetivação do seu pagamento já foi reservado no orçamento do órgão público.

0 empenho dá a garantia para o fornecedor vender seus produtos a administração pública, o empenho é confeccionado após o ato licitatório ser finalizado, e contrato administrativo ser homologado, mediante ordem de serviço solicitado pelo ordenador de despesa, essa é dirigida ao setor de contabilidade ou correspondente onde será providenciado o empenho prévio, (antes de comprar o produto/serviço) para só então o responsável pela compra se dirigir a empresa com a ordem de serviço assinada pelo ordenador da despesa juntamente com a nota de empenho. Esse pode ser ordinário que é quando a empresa fornece um produto eventual emitido com nota fiscal reconhecida pelo administrador de contratos. 0 empenho pode ser global que corresponde ao reconhecimento de uma despesa anual que é fracionada em pagamento mensais de igual valor como aluguel. E por último o empenho estimativo que é utilizado para os casos que a despesa é continua, mas não existe um valor fixo a ser paga e nem tem como mensurar o valor exato anual, como é o caso das despesas com energia elétrica.

O empenho é o primeiro estágio da despesa pública e quando esse é entregue ao fornecedor juntamente com a ordem de compra, esse tem um prazo, estimado no objeto de contrato para comparecer com os produtos no setor solicitante, juntamente com os documentos fiscais e certidões de regularidade fiscal. Ainda segundo SANTOS $(2012$, p. 45)

a liquidação é o reconhecimento de que os bens ou serviços adquiridos foram entregues conforme previa o contrato e que, portanto, o contratado é credor da Administração Pública e tem direito ao pagamento correspondente. Para liquidar a despesa, o gestor público deve verificar se o contratante atendeu às condições do contrato e apurar quem é o credor e qual o montante do pagamento a ser realizado.

O contrato supracitado é a forma pela qual, ambas as partes, Prefeitura e Fornecedor, por exemplo, firmam perante documentação exigida pelo contratante que no caso da gestão pública é o ente público, os termos do contrato através de clausulas que estabelecem prazos e condições exigidas por ambas às partes para cumprimento e benefício mutuo tanto do órgão como do credor, esse contrato é confeccionado através de processo licitatório.

Após a entrega dos produtos correspondendo com o solicitado juntamente com as certidões de regularidade fiscal, o recebimento das mercadorias implicara no início do processo de liquidação da despesa. Após o fornecedor entregar a mercadoria, essa passará ao status de em liquidação, que é o prazo determinado para que gestor de contratos verifique se as mercadorias entregues estão compatíveis com as solicitadas na ordem de compra ou serviço e de acordo com o objeto que foi licitado. Esse processo é regulamentado pelo ente público onde o mesmo estipulara o tempo necessário para efetuar a liquidação da despesa, fato que segundo recomendações estaduais no caso do RN não deverá passar dos quatorze dias após a entrega da mercadoria. Finalizado o processo de liquidação 
onde o gestor de contratos expressa a afinidade do cumprimento do contrato, esse fato é apresentado ao responsável legal para que a despesa seja apensada como liquidada no sistema contábil financeiro e a partir desse momento o credor pode protocolar a sua cobrança dos seus valores devidos por parte do Estado, a secretaria do tesouro nacional expressa na sua página uma parte do artigo que regulamento o processo de liquidação.

O processo de liquidação envolve, portanto, todos os atos de verificação e conferência, desde a entrega do material ou a prestação do serviço até o reconhecimento da despesa. Ao fazer a entrega do material ou a prestação do serviço, o credor deverá apresentar a nota fiscal, fatura ou conta correspondente, acompanhada da primeira via da nota de empenho, devendo o funcionário competente atestar o recebimento do material ou a prestação do serviço correspondente, no verso da nota fiscal, fatura ou conta. (BRASIL, 2017).

A partir da liquidação o fornecedor entra em uma ordem cronológica organizada por fontes de recurso juntamente com outros fornecedores para aguardar o seu pagamento.

O pagamento é a parte que a administração providencia através de transferências ou emissão de cheques para pagar seus dividendos ao credor que fornecera seus produtos ao Estado.

No âmbito do estado do RN, foi instituída a RESOLUÇÃO Nº32/2016- TCE, de 06 de setembro de 2016.

Dispõe sobre os critérios para pagamento, em ordem cronológica, das obrigações financeiras devidas pelo Tribunal de Contas do Estado do Rio Grande do Norte, nos termos do art. $5^{\circ}$ da Lei $n^{\circ}$ 8.666, de 21 de junho de 1993, e dá outras providências. (TCE/RN, 2016, p 01)

O pagamento é a emissão de uma ordem de pagamento (cheque, ordem bancária ou outro meio de pagamento) em favor do credor que a reserva orçamentária foi efetuada através do empenho e a liquidação do produto ou serviço foi checado através da liquidação.

A ordem cronológica orienta o pagamento por ordem de liquidação dos pedidos efetuados pela gestão pública, podendo os gestores sofrer penas previstas na lei orgânica do TCE/RN caso venham a descumprir a ordem de pagamentos evidenciada por esse instrumento de regulamentação jurídica.

Art. 5o Todos os valores, preços e custos utilizados nas licitações terão como expressão monetária a moeda corrente nacional, ressalvado o disposto no art. 42 desta Lei, devendo cada unidade da Administração, no pagamento das obrigações relativas ao fornecimento de bens, locações, realização de obras e prestação de serviços, obedecer, para cada fonte diferenciada de recursos, a estrita ordem cronológica das datas de suas exigibilidades, salvo quando presentes relevantes razões de interesse público e mediante prévia justificativa da autoridade competente, devidamente publicada. (BRASIL, 1993) 


\section{ISSN - 2447-178X}

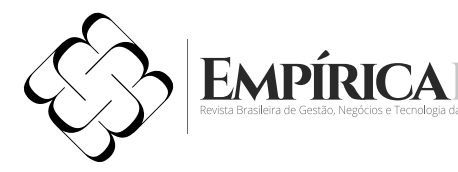

A ordem cronológica de pagamento está presente na constituição desde 1993 regulamentando os pagamentos da gestão pública, porém não estava sendo cumprido pelos entes da federação, fato esse que os órgãos fiscalizadores atentaram e regulamentaram através de instrumentos normativos a aplicabilidade dessa ordem cronológica de pagamento que entra em vigor no estado do Rio Grande do Norte a partir de 01 de setembro de 2017.

Art. $1^{\circ} \mathrm{A}$ presenteResolução instituiprocedimentos, rotinas, devereseresponsabilidades para a adequada observância da ordem cronológica de pagamentos de obrigações de natureza contratual e onerosa firmados por cada unidade da Administração Pública pertencente ao Estado do Rio Grande do Norte e a qualquer dos seus Municípios, com vistas ao cumprimento ao art. $5^{\circ}$ da Lei $n^{\circ} 8.666$, de 21 de junho de 1993, bem como estabelece diretrizes para a edição de regulamentos próprios acerca da matéria por parte dos jurisdicionados do Tribunal de Contas do Estado.(TCE/RN, 2016, p 02)

A ordem cronológica assinala entre os seus objetivos orientar e organizar a execução da despesa pública, prevista desde 1993 na constituição, possibilitando que os fornecedores não sejam lesados pelo poder público onde fiquem esperando por meses os seus pagamentos, através desse instrumento normativo os gestores deverão cumpri-lo estritamente, caso contrário serão penalizados de acordo com a gravidade do fato. Outro ponto que a resolução agrega a gestão pública é o fato de que os gestores deverão fazer um planejamento minucioso na hora de empenhar suas despesas acima do que o município pode pagar, pois com a ordem cronológica a fiscalização da despesa se tornará mais intensa tanto por parte dos fornecedores como dos órgãos fiscalizadores.

\section{METODOLOGIA}

O trabalho enfoca principalmente a importância do empenho, o ato do recebimento das mercadorias classificado como liquidação e o pagamento.

Essa pesquisa se caracteriza como descritiva, pois descreve as características inerentes ao contexto do orçamento público baseando-se nas referências estudadas e leis implantadas tanto na esfera federal como estadual. Com relação aos métodos empregados, de início foram coletadas informações essenciais através de fontes como sites da internet, artigos publicados em site da área, livros, para obter informações sobre a área pesquisada, ou seja, foi realizada uma pesquisa bibliográfica, onde as ferramentas utilizadas foram computadores com acesso à internet para viabilizar o acesso aos conteúdos digitais e livros que contém os assuntos estudados e as informações essenciais para o andamento do estudo.

Ainda na caracterização, pode-se afirmar que foi feito um estudo de caso, pois, para Zanella (2012, p. 84): 


\section{ISSN - 2447-178X}

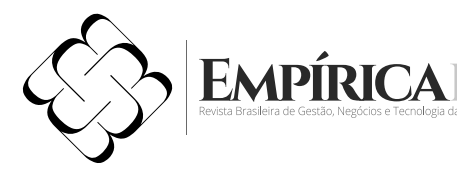

conhecer em profundidade a realidade de uma pessoa, de um grupo de pessoas, de uma ou mais organizações, uma política econômica, um programa de governo, um tipo de serviço público, entre outros. Assim, a característica principal é a profundidade do estudo.

Um estudo de caso é uma investigação empírica que investiga um fenômeno contemporâneo dentro de seu contexto da vida real, especialmente quando os limites entre o fenômeno e o contexto não estão claramente definidos; Enfrenta uma situação tecnicamente única em que haverá muito mais variáveis de interesse do que pontos de dados; Baseia-se em várias fontes de evidências; e, como outro resultado; e Beneficia-se do desenvolvimento prévio de proposições teóricas para conduzir a coleta e análise de dados (Yin 2001, p. 32).

Finalizada a pesquisa bibliográfica que compreende o levantamento de informações expostas em documentos e posteriores o estudo de caso que visa aprofundar mais o conhecimento acerca do assunto estudado, o trabalho segue com as discussões que estabelecem com base nas referências analisadas a opinião do pesquisador sobre a importância do estudo, seguindo com as conclusões que fecha a discussão, podendo deixar temas abertos para futuras pesquisas de adeptos a esse tema tão importante que é o gasto do dinheiro público por parte dos nossos governantes.

0 instrumento aplicado para coletar de dados foi um questionário contendo dez perguntas objetivas.

\section{RESULTADOS E DISCUSSÕES}

Alçada a discussão tendo como base a opinião de autores e entidades que pesquisaram sobreo assunto proposto no presente estudo, segue a necessidade de formular o pensamento dos resultados e enfocar nos objetivos da pesquisa que são aprimorar o conhecimento acerca dos três estágios da despesa pública tendo como enfoque estratégico otimizar o tempo necessário para trabalhar a burocracia de uma forma mais eficiente e eficaz para melhorar o andamento dos processos e conscientizar os servidores públicos e sociedade da importância de fiscalizar esses estágios.

Quando se fala em trabalhar o empenho, liquidação e pagamento como ferramenta estratégica para aperfeiçoar os serviços públicos, pressupõe-se que existe algum ponto onde se deseja chegar, uma meta ou uma problemática que necessita ser revisada e colocada em questão, planejar é determinar o caminho para chegar de forma mais eficiente e eficaz a um objetivo comum que no caso da gestão pública é a prestação de serviço de qualidade para a sociedade. Afinal, os gestores não são gestores públicos, eles estão gestores e quando entram na vida pública assumem a responsabilidade de trabalhar por todos e para todos.

Trabalhar o empenho estrategicamente é fazer com que o fluxo e as reservas orçamentárias sejam executadas de forma correta e prévia, contemplando os fornecedores com mais segurança na hora de fornecer os produtos/serviços podendo também proporcionar aos gestores a garantia de que não foram empenhadas dividas acima do previsto no instrumento de planejamento já visto anteriormente, fato que se identificado pelos órgãos fiscalizadores pode ocorrer limite de empenho para não extrapolar as previsões de receitas e comprometer os orçamentos com índices acima dos aceitáveis estipulados pelas leis. 


\section{ISSN - 2447-178X}

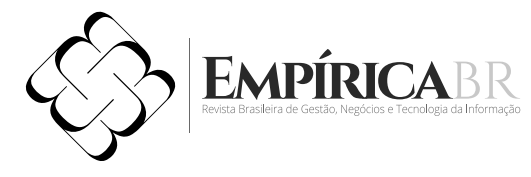

O empenho trabalhado de forma estratégica proporciona para o gestor informações sobre as despesas solicitadas pelos seus secretários, podendo controlar saldos de licitações, valores das despesas.

As Despesas são os desembolsos efetuados pelo Estado para fazer face as suas diversas responsabilidades junto à sociedade. As Despesas são classificadas quanto à natureza em despesas orçamentárias e extra-orçamentárias. As despesas orçamentárias passam por quatro estágios: fixação, que consiste no valor total da despesa prevista na LOA; empenho, que consiste no ato emanado da autoridade competente que cria para o Estado, a obrigação de pagamento pendente ou não de implemento de condição; liquidação, que consiste na verificação do direito adquirido pelo credor, tendo por base os títulos e documentos do respectivo crédito; e pagamento, entrega do numerário correspondente, recebendo a devida quitação. A Lei de Responsabilidade Fiscal estabeleceu regras para que os gestores obtenham uma gestão administrativa comprometida com o equilíbrio orçamentário, com vista a fomentar o crescimento da receita e a controlar o montante da despesa pública, para isto estabeleceu medidas de limitação de empenho de despesa, bem como regras para geração de novas despesas. (KARINY, HELCIAS, 2013, p 54)

O empenho utilizado de forma equivocada pode acarretar em restrições a partir de um determinado período numa gestão, podendo comprometer serviços essenciais que deixariam de ser ofertados à população devido à utilização errada desse estágio da despesa pública. 0 empenho deve ser solicitado de forma planejada, pautado por indicadores e justificativas que contemplem a aplicabilidade dos recursos empenhados (KARINE e HELCIAS 2013, p. 8).

O segundo estágio da despesa pública é a liquidação que é o recebimento da mercadoria empenhada e solicitada aos credores por meio de ordens de compras ou serviços, esse ponto é coordenado pelos editais de licitação e contratos administrativos que estipulam prazos para a entrega da mercadoria a partir do recebimento da ordem de compra e prazos para pagamento posteriores o recebimento dos produtos solicitados, a liquidação é documentada pelo gestor de contratos dos órgãos que atesta perante documento o recebimento fidedigno dos produtos de acordo com o estipulado no edital de licitação, esse setor de liquidação também é o responsável pela verificação da regularidade da empresa perante os tributos municipais, estaduais e federais, podendo reprimir o andamento do processo na hora da liquidação, antes de receber os produtos. A liquidação ganha a partir do ano de 2017, mais precisamente no estado do RN uma importância evidente com a chegada da ordem cronológica, citada anteriormente, onde por meio de uma resolução o estado do RN estipula para os municípios do estado o cumprimento da ordem cronológica de pagamento por fonte de recurso.

Com a resolução os municípios terão obrigação de efetuar os pagamentos em ordem cronológica, ficando impedidos de pagará credores que não estejam na 'fila' de espera desse método, o processo será organizado a partir da liquidação dos produtos, quem entregar seus produtos primeiro receberá 
o pagamento primeiro. Caso a ordem seja quebrada, o gestor ficará propenso a penas previstas na lei orgânica do TCE/RN. Com a chegada dessa resolução, a liquidação toma novos rumos, ganhando ainda mais importância no estágio da despesa pública, e estimulando os credores a aperfeiçoarem a sua logística para que recebam seus montantes o quanto antes.

Para que o processo funcione corretamente, tenha em vista a necessidade de estrutura para funcionamento do setor de liquidação juntamente com o almoxarifado, e principalmente capacitação para os responsáveis por esse setor.

Art. $5^{\circ} \mathrm{O}$ estabelecimento do procedimento de liquidação da despesa iniciar-se- á a partir do protocolamento por parte do credor da solicitação de cobrança, efetuado junto a setor competente definido no âmbito de cada unidade gestora e, obrigatoriamente, identificado em cláusula do instrumento de contrato, ao qual competirá a efetuação imediata do lançamento do beneficiário do documento de cobrança na lista geral e/ou específica de credores que protocolaram documentos de cobrança. Parágrafo único. A solicitação de cobrança de que trata o caput será acompanhada de nota fiscal, fatura ou documento equivalente, além de qualquer outra espécie de documentação porventura exigida no instrumento contratual. (TCE/RN, 2016, p 4)

O pagamento é a ordem executada para transferência do recurso da conta da entidade pública para a conta do fornecedor, esse procedimento pode ser executado por transferências bancarias ou emissão de cheques nominais a empresa. Quando o pagamento é efetuado, lançado no sistema é dado baixa no empenho e liquidação, ficando o município quite com o fornecedor. Os recursos para pagamento desse débito foram vinculados na hora do empenho, esses podem ser segundo o TCE/ RN, recursos vinculados: os recursos provenientes de contratos de empréstimo ou de financiamento, de convênios, de emissão de títulos ou de qualquer outra forma de obtenção de recursos que exija aplicação vinculada à finalidade específica. E recursos não vinculados: os recursos oriundos de receita própria, de transferências ou de outros meios para os quais não se ache vinculada especificamente sua aplicação.

O terceiro estágio da despesa pública é o mais simples no ponto de vista organizacional e operacional do processo, porém se os outros estágios não estiverem conciliados e funcionando em harmonia, o pagamento pode ser efetuado de forma errônea podendo quebrar, por exemplo, a ordem cronológica ou até mesmo efetuar um pagamento baseado na nota de empenho que esteja com os valores errados.

O andamento dos processos e o fluxo organizacional são burocráticos como apontado desde a nota de empenho que é o primeiro estágio da despesa pública até para chegar ao ato final dos três estágios que é o pagamento, porém é uma burocracia necessária para o andamento correto das atividades dos órgãos públicos. Essa burocracia é demandada de um sistema complexo de gestão pública que o nosso país é seguidor, entretanto a caminhada para amenizar a burocracia e otimizar o fluxo para que os processos andem de maneira mais rápida é a capacitação dos servidores e 


\section{ISSN - 2447-178X}

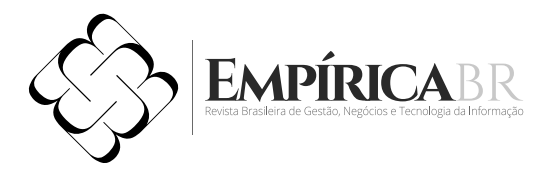

população, o conhecimento é a chave para que o país avance com efetividade e os gestores e servidores capacitados conduzirão o país embasados no conhecimento e informação.

Partindo do objetivo de identificar melhor o perfil do agente público que trabalha com a burocracia, evidencia-se a necessidade de aplicar um instrumento para delimitar o perfil dos indivíduos que trabalham com o fluxo estudado no trabalho, para tal foi aplicado um questionário contendo dez perguntas objetivas onde se buscou compreender melhor o funcionamento dessa burocracia que faz parte do ambiente de trabalho dos servidores públicos que trabalham com orçamento.

A idade média dessas pessoas que trabalham com a parte burocrática foi estimada em 27 anos evidenciando assim um público relativamente jovem, sendo composto em sua maioria por homens, mais precisamente $55 \%$ dos respondentes.

Quando perguntados sobre as qualificações profissionais evidencia-se que o grau de instrução do público que respondeu o questionário é constituído de pessoas capacitadas que tem formações nas mais variadas áreas e níveis desde cursos técnicos até pós graduações, como demonstra o quadro abaixo.

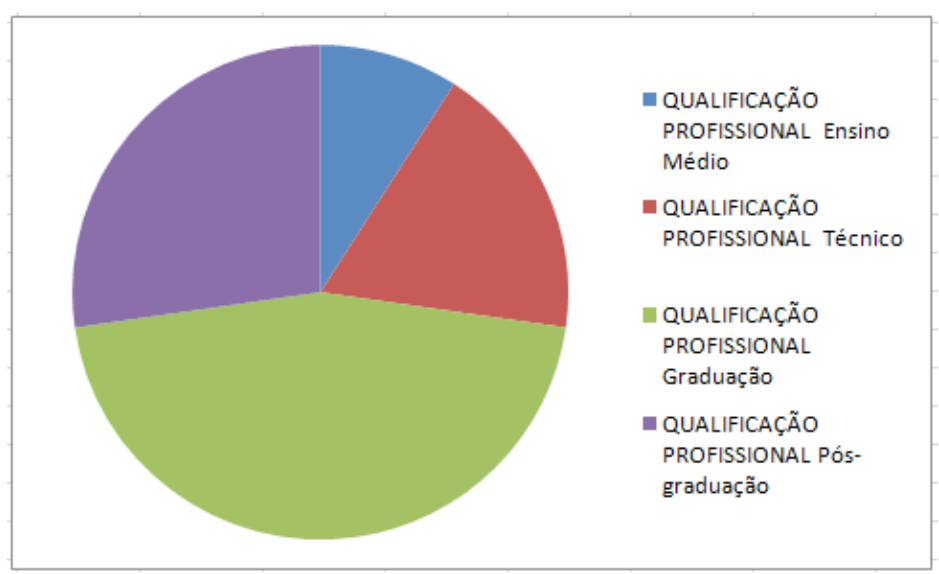

Fígura 1 : com grau de instrução dos entrevistados;

Fonte: elaboração própria

Analisando o quadro acima, nota-se que o perfil dos entrevistados é constituído de pessoas qualificadas com cursos superiores e técnicos. Outra informação que se destaca entre os dados coletados é o fato de que apenas quatro pessoas das onze responsáveis por trabalhar com orçamento público ingressaram na administração pública através de concurso público, como demonstra o quadro dois abaixo. 


\section{ISSN - 2447-178X}

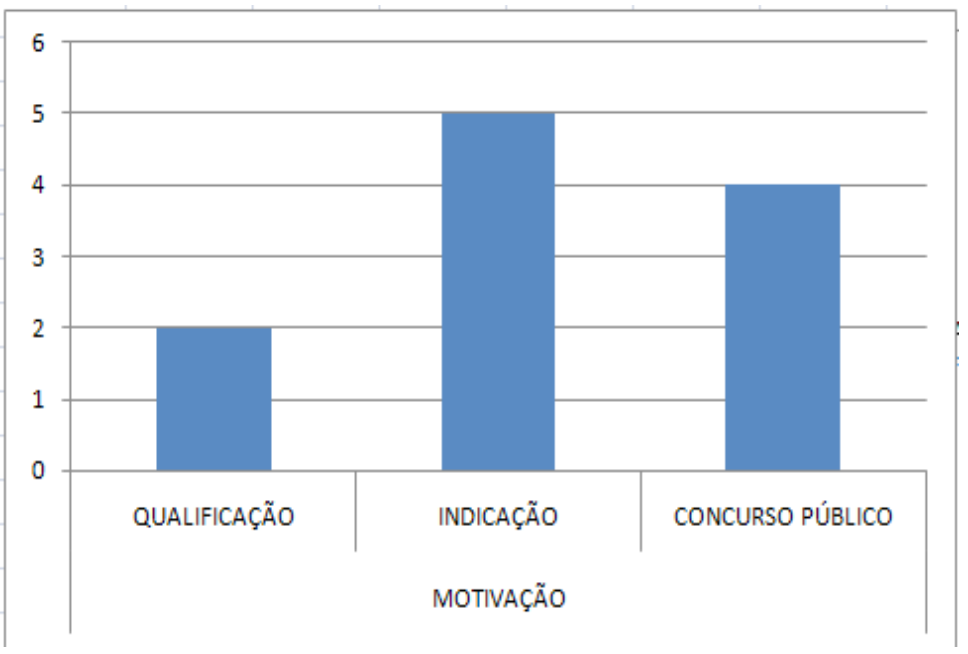

Fígura 2: que demonstra a motivação do ingresso na administração pública;

Fonte: Elaboração própria.

Os dados acima demonstram a realidade de muitos municípios e estados onde a execução da despesa e o andamento das atividades são coordenadas por pessoas que foram indicadas por políticos, essas exercem cargos de livre nomeação e isso é o que preocupa e compromete o futuro dos municípios, afinal uma gestão é temporal e trabalha sobre os interesses e planejamento dela, muitas vezes a continuidade dos trabalhos são comprometidos como pode-se visualizar através do exemplo de inúmeras obras paradas por falta de recurso ou falha na execução dos orçamentos, só no estado do RN, o Tribunal de Contas do Estado (TCE/RN) identificou num estudo feito desde 2015 um potencial dano de R\$ 308 milhões investidos em 313 obras paralisadas e inacabadas. Os dados integram um relatório sobre obras relevantes, com valores acima de R\$ 50 mil, que não foram concluídas em 100 municípios do Estado, as obras estariam vinculadas aos mais diversos setores e serviços que possibilitariam a melhoria das condições de vida de boa parte da sociedade nos municípios potiguares como esgotamentos sanitários, escolas, creches, praças esportivas etc. Ao apresentar os dados o conselheiro FILHO (2017) enfatiza:

"No momento da elaboração da lei de diretrizes orçamentárias, os chefes dos poderes Executivo e Legislativo devem observar as disposições contidas na Lei de Responsabilidade Fiscal, de modo que sejam consideradas as exigências necessárias ao atendimento dos projetos em execução e, na elaboração da respectiva lei orçamentária anual, os recursos indispensáveis ao seu prosseguimento e à sua conclusão", recomenda o conselheiro, no seu voto, acrescentando também "a urgente a necessidade de se promover melhorias nas ações, rotinas e procedimentos relacionados ao controle e ao monitoramento das obras públicas”. 


\section{ISSN - 2447-178X}

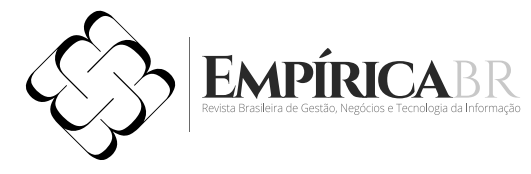

Os municípios ficam muitas vezes reféns do conhecimento represado nas mãos de pessoas que se vão junto com uma gestão ao termino do seu mandato. Analisado o perfil desses servidores, até o momento evidenciam-se pessoas capacitadas com um bom grau de instrução que estão à frente da gestão orçamentária, porém são em sua maioria pessoas indicadas para o cargo ao qual estão ocupando. Com relação à remuneração e as exigências do cargo 75\% dos servidores estão satisfeitos com remuneração recebida por seu trabalho prestado ao universo em que o questionário foi aplicado.

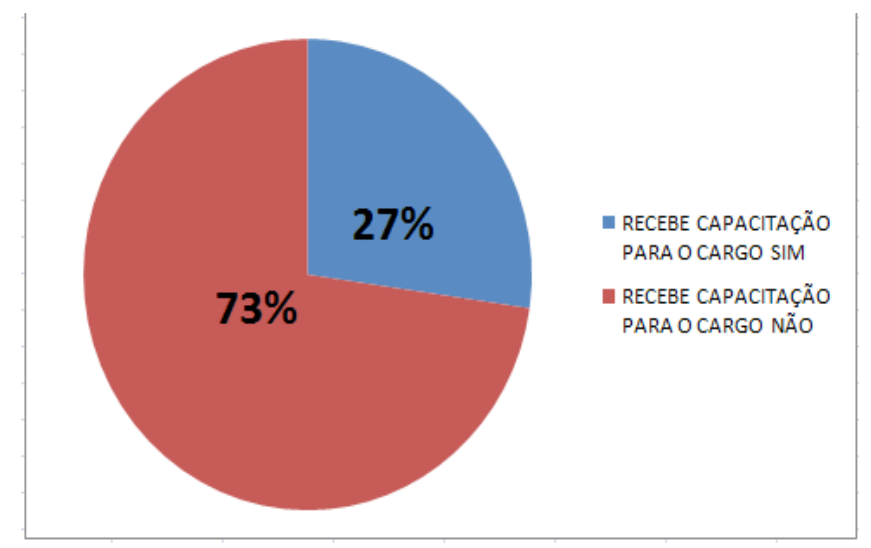

Fígura 3: Dados sobre o programa de qualificação do servidor após investidura ao cargo;

Fonte: Elaboração própria.

Os dados demonstrados no quadro três são preocupantes partindo da premissa de que apenas $27 \%$ dos indivíduos responsáveis pelo andamento e execução da despesa pública receberam capacitações após ocuparem o cargo que fora investido, por intermédio de concurso público ou indicação. Esse ponto ganha destaque na pesquisa como uma falha a ser corrigida pelos setores públicos onde a falta de capacitação compromete a prestação dos serviços públicos e facilita as fraudes ao erário público. Uma vez que o funcionário sem informação não saberá se está fazendo um trabalho da forma correta, de acordo com o que manda a constituição e os instrumentos utilizados que regulamentam o que a gestão pública pode fazer, segue abaixo um pensamento que esclarece mais o tema discutido.

A capacitação e formação de servidores públicos é tema que vem ganhando maior expressividade no Brasil, principalmente após o advento das reformas do Estado, ocorrida na década de 1990. A nova configuração da função estatal demandou melhorias na prestação de serviços, gerando pressão para uma maior qualificação de servidores públicos. Para atender a estas demandas foram criadas "escolas de governo" nos diversos entes federativos e poderes governamentais. Ganharam expressividade também as experiências de profissionalização para o setor público estabelecidas fora dos espaços de governo, por meio de instituições de ensino superior, universidades corporativas, organizações não governamentais e fundações partidárias. O conceito de escola de governo admite uma 


\section{ISSN - 2447-178X}

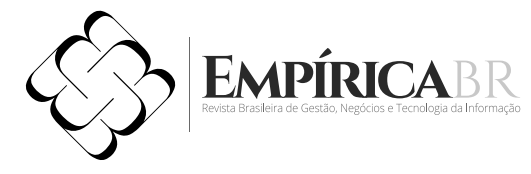

multiplicidade de organizações, com experiências variadas e com aspectos diferentes, mas, com propósitos, muitas vezes, comuns. (DE SENNE RANZINI, 2017, p. 419)

No século 21 com a modernização e o acesso mais rápido aos mais diversos meios de comunicação e interação oportunizando aos que desejam se capacitar adquirir o conhecimento sem precisar sair de casa, como é o caso do programa de capacitação para os gestores públicos promovido pela UAB juntamente como o IFRN, o conhecimento existe e deve ser multiplicado para que a gestão pública tome rumos diferentes e prospere nesses tempos turbulentos, só através da educação que uma nação cresce, o povo deve conhecer e aprender sobre as políticas públicas para saber cobrar melhor dos seus representantes, e das pessoas que estão à frente dos serviços públicos.

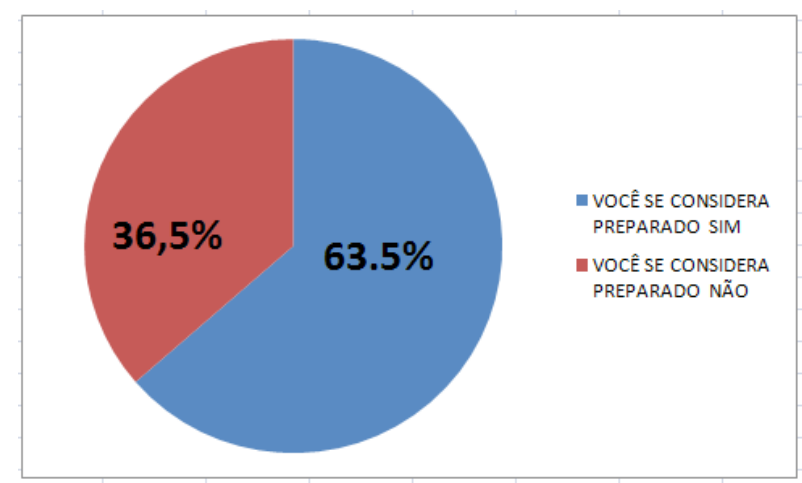

Fígura 4:Você acredita que seus conhecimentos são suficientes para exercer o seu cargo?

Fonte: Elaboração própria.

Embora tenha sido demonstrado anteriormente no estudo que a maioria dos servidores não foram capacitados para seus cargos, $63,5 \%$ consideram-se preparados para exercer o cargo público que estão a frente, dado que demonstra comodismo das pessoas que não buscam a informação e a capacitação necessária para exercer as atividades que são de sua responsabilidade, mais especificamente o público alvo analisado no referido trabalho que são os servidores responsáveis pelo execução dos três estágios da despesa pública. No tocante a capacitação e as motivações para buscar a capacitação vale salientar que a maioria das pessoas que responderam às perguntas foram nomeados para cargos de livre nomeação evidenciando assim a inexperiência podendo comprometer o andamento das atividades na gestão pública. 


\section{ISSN - 2447-178X}

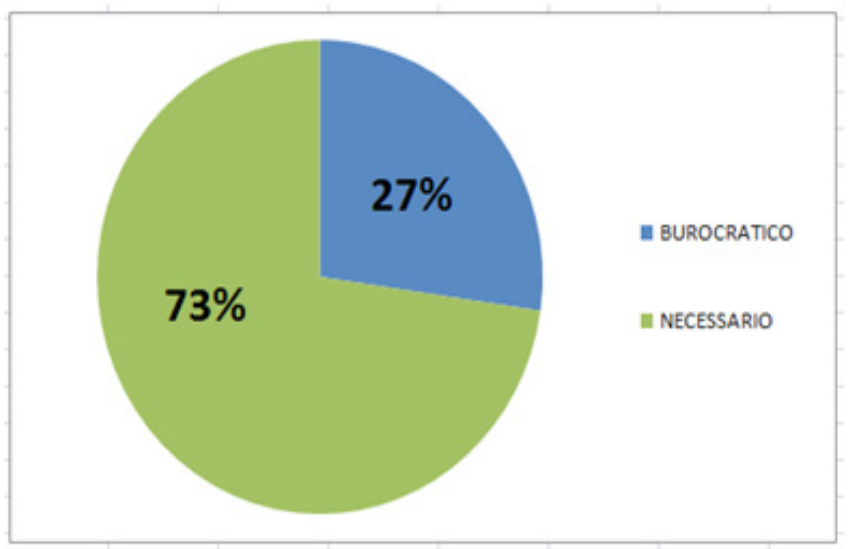

Fígura 5:Opinião dos entrevistados sobre os três estágios da despesa pública.

Fonte: Elaboração própria.

Os dados acima finalizam a coleta das informações onde pode-se notar que $73 \%$ do universo pesquisado acreditam que os três estágios da despesa pública são necessários para a administração pública como uma ferramenta que proporciona transparência e legalidades na hora do governo adquirir seus bens ou serviços. A gestão pública é burocrática como foi visto anteriormente, porém é um campo de estudo interessante onde não conseguimos evidenciar inovações e pesquisas que proporcionem agilizar os processos dentro do ambiente de trabalho. Concluindo a análise dos dados nota-se que a problemática do trabalho evidencia-se totalmente no quadro três onde $73 \%$ das pessoas investidas no cargo público não receberam capacitações após serem nomeadas para prestar um serviço tão importante para a sociedade que é a execução dos três estágios da despesa pública, pode-se notar também que $63,5 \%$ acreditam terem o conhecimento necessário para exercer o cargo, fato que demonstra comodidade por parte desse público na busca do conhecimento para que possam desenvolver suas atividades com mais eficiência, fato é que a administração pública é regida por leis e atos normativos que mudam constantemente onde dizem o que pode e não pode fazer, os orçamentos são planejados anualmente podendo ser ajustados no decorrer do ano. 0 funcionário deve estar atento e em capacitação continua sempre para que saiba o que está fazendo na hora de exercer as suas funções, caso contrário pode fazer suas atividades e está infringindo alguma lei podendo prejudicar-se assim também como a sociedade.

Os três estágios da despesa pública são regulamentados de tal forma que os gestores sigam os cinco princípios da gestão pública que é a Legalidade, Impessoalidade, Moralidade, Publicidade e Eficiência, toda atitude tomada pelos gestores públicos ou servidores deve sempre seguir esses cinco princípios, e pensando assim os três estágios da despesa foram pensados e estruturados de tal forma que o seu fluxo seja seguido da forma mais eficiente possível, sempre com transparência e impessoalidade. Fato é como demonstrado aqui que deve haver o interesse mutuo de promover o conhecimento tanto dos servidores como dos gestores para que essas pessoas saibam como que estão trabalhando e como fazer para que o processo ande o mais rápido possível, só o conhecimento poderá mudar essa realidade desse sistema burocrático adotado por nossa constituição. 


\section{CONCLUSÕES}

Finalizada a parte do trabalho que trata da discussão acerca do ponto central do trabalho, torna-se claro e cada vez mais evidente a importância de trabalhar e aprofundar a pesquisa sobre o orçamento público e como os programas de capacitações das pessoas que trabalham com sua execução evidenciando a periodicidade das capacitações e mensurando o retorno e a eficiência após os servidores serem capacitados, proporcionando assim mais eficiência para lidar com os procedimentos de compras dos produtos/serviços na gestão pública.

A sociedade cobra políticas públicas mais eficientes e transparentes, participando da formulação de orçamentos, fiscalizando os gestores e esse ponto pode contribuir para uma mudança do cenário atual em que o Brasil se encontra. Uma sociedade provida de informação consegue mudar o destino do seu Estado, o estudo desenvolvido nessas linhas evidenciou informações pertinentes ao processo de compras regulamentado por leis federais e estaduais previstas na constituição e tribunais de contas, apesar do avanço que diz respeito à transparência e conhecimento, o brasileiro ainda busca pouco por informações acerca da gestão pública, existe a necessidade de uma participação mais expressiva nas confecções dos orçamentos, no acompanhamento da execução e na cobrança aos gestores que tem o poder de gerir os recursos da sociedade.

Concluindo, pode-se dizer através do estudo feito, que existe um déficit de capacitações para com as pessoas que trabalham com a execução do orçamento. As informações analisadas contribuirão para futuras pesquisas orientando os pesquisadores a desenvolverem trabalho nessa área de raciocínio. Dentre as limitações dessa pesquisa, destacam-se as restrições de referências e dados estatísticos para trabalhar o assunto proposto.

Sugere-se que seja realizado um estudo de caso para identificar o progresso e a evolução da aplicação e organização dos setores de empenho, liquidação e pagamento compreendendo o período que vai de antes da lei que regulamenta a ordem cronológica a depois da implantação dos setores e exigência do cumprimento da mesma. 0 recurso gerido por nosso representante é da sociedade e como tal a sociedade tem o dever de fiscalizar, não apenas os gestores, mas os servidores também, quando investidos para o cargo público os servidores tem como objetivo servir a sociedade e caso venham a infringir alguma lei que cause danos ao erário deve ser responsabilizado assim como os políticos. Ainda sobre possíveis estudos a serem realizados evidencia-se a necessidade de aprofundar o tema que trata da capacitação dos servidores, fato que é demonstrado no trabalho através de informações levantadas mediante pesquisa.

\section{REFERÊNCIAS}

1. BRASIL, Tesouro Nacional. Execussão orçamentária, Secretaria do Tesouro Nacional, 2017. Disponível em: <http://www.tesouro.fazenda.gov.br/en/execucao-orcamentaria>. Acesso em: 18set. 2017.

2. BRASIL. Lei $n^{\circ} 11.653$, de 7 de abril de 2008. Diário Oficial da União, Brasília, DF, nº 67, terçafeira, 8 de abril de 2008. Seção 1, p. 5 


\section{ISSN - 2447-178X}

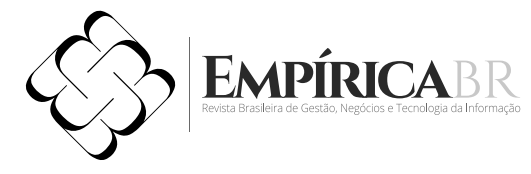

3. CARVALHO, Maria Balbina. A gestão de compras e o processo de licitação no setor público. Caderno de Graduação-Ciências Humanas e Sociais-UNIT, v. 4, n. 1, p. 165, 2017.

4. DE SENNE RANZINI, Milena; BRYAN, Newton Antonio Paciulli. Capacitação e formação para o setor público e os modelos de escola de governo no Brasil. Revista do Serviço Público, v. 68, n. 2, 2017.

5. DE SOUZA, Fábio Jacinto Barreto et al. Orçamento Participativo: Mais qualidade da democracia?. Organizações\&Sociedade, v. 24, n. 81, 2017.

6. DE VASCONCELOS, Flávio Carvalho. Racionalidade, autoridade e burocracia: as bases da definição de um tipo organizacional pós-burocrático. Revista de Administração Pública, v. 38, n. 2, p. 199-220, 2004.

7. FEITOSA, Anny Kariny; OLIVEIRA, Fabiana Helcias. CONTROLE DO ORÇAMENTO PÚBLICO MUNICIPAL. A EconomiaemRevista-AERE, v. 21, n. 2, p. 49-60, 2016.

8. FILHO, Jorge. TCE aponta que obras paralisadas no RN representam potencial dano ao erário de R\$ 308 milhões, Tribunal de Contas do RN, 2017. Disponível em: <http://www.tce.rn.gov.br/Noticias/ NoticiaDetalhada/3424>. Acesso em: 17 set. 2017.

9. MANAF, Marcos Aurélio; SILVA, Juvencio Borges. A BUROCRACIA DO ESTADO BRASILEIRO COMO OBSTÁCULO À CONCREÇÃO DOS DIREITOS SOCIAIS: UMA AVALIAÇÃO DA ORGANIZAÇÃO DA SOCIEDADE CIVIL DE INTERESSE PÚBLICO (OSCIP) E DA ORGANIZAÇÃO SOCIAL (OS). Revista de Estudos e Pesquisas Avançadas do Terceiro Setor, v. 4, n. 1 JAN/JUN, p. 170-197, 2017.

10. SANO, Hironobu; MONTENEGRO FILHO, Mário Jorge França. As técnicas de avaliação da eficiência, eficácia e efetividade na gestão pública e sua relevância para o desenvolvimento social e das ações públicas. Desenvolvimento em Questão, v. 11, n. 22, p. 35-61, 2013.

11. SANTOS, RITA DE CASSIA. Plano plurianual e orçamento público / Rita de Cássia Santos. - 2. ed.reimp. - Florianópolis: Departamento de Ciências da Administração / UFSC; [Brasília] : CAPES : UAB, 2012. 152p. :

12. YIN, Robert K. Estudo de caso: planejamento e métodos. 2. ed. Porto Alegre: Bookman, 2001.

13. ZANELLA, Liane Carly Hermes. Metodologia de estudo e de pesquisa em administração. Florianópolis: Departamento de Ciências da Administração/UFSC, 2009. 